\title{
Improvement the Plasticity via Dual-Amorphous and Nanocrystals Synergistically in a Zr-Cu-Al-Nb Bulk Metallic Glass Composite
}

\author{
Tuo Wang ${ }^{1, *}$, Xiaohui Yang ${ }^{2}$, Qiang Li $^{1}$ (I) and Chuntao Chang ${ }^{3}$ \\ 1 School of Physics Science and Technology, Xinjiang University, Urumqi 830046, China; qli@xju.edu.cn \\ 2 Instrumental Analysis Center, Taiyuan University of Science and Technology, Taiyuan 030024, China; \\ xhyang@tyust.edu.cn \\ 3 School of Mechanical Engineering, Dongguan University of Technology, Dongguan 523808, China; \\ changct@dgut.edu.cn \\ * Correspondence: wangtuo@xju.edu.cn
}

Received: 13 July 2020; Accepted: 19 August 2020; Published: 27 August 2020

\begin{abstract}
In this work, a small amount of $\mathrm{Nb}$ has been added in a $\mathrm{Zr}_{52} \mathrm{Cu}_{42.5} \mathrm{Al}_{5.5}$ bulk metallic glass, and a $\mathrm{Zr}_{52} \mathrm{Cu}_{42} \mathrm{Al}_{5.5} \mathrm{Nb}_{0.5}$ bulk metallic glass composite with dual-amorphous and nanocrystal structures has been developed for the first time. This in situ formed bulk metallic glass composite has a larger room compressive plasticity of above $13 \%$ than that of the $\mathrm{Zr}_{52} \mathrm{Cu}_{42.5} \mathrm{Al}_{5.5}$ bulk metallic glass. The excellent plasticity of the bulk metallic glass composite is attributed to the phase-separated matrix with micro-nanocrystal and the nanocrystallization during the deforming process. This work may give a new sight into design bulk metallic glass composites and the underlying mechanism for deformation.
\end{abstract}

Keywords: bulk metallic glass composite; plasticity; dual-glass; nanocrystallization

\section{Introduction}

Bulk metallic glasses (BMGs) have potential applications because of its many excellent properties, such as high strength, large elastic strain limit, good corrosion resistance [1-5], etc. However, most BMGs tend to be highly localized into narrow shear bands, resulting in a poor macroscopic plasticity or toughness at room temperature before its fracture. For example, there is less than $2 \%$ plastic deformation for the commercial Vit 1 [6]. Most of the rare-earth and iron-based BMGs $[7,8]$ have near zero plasticity and fracture toughness at room temperature.

Improving the plasticity at room temperature of MGs has been a major issue for comprehensively understanding the plasticity and physical property of MGs [9]. Among the methods $[10,11]$ that have been put forward to enhance the plasticity in existence, phase separation and in suit formed bulk metallic glass (BMG) composite are the two most widely used. Both of them are based on the introduction of structural heterogeneity in BMGs. However, some phase-separated alloys with large wavelengths such as the plasticity of $\mathrm{Zr}_{46} \mathrm{Cu}_{42} \mathrm{Al}_{7} \mathrm{Y}_{5}$ BMG exhibits less than 2\% [12]. A high degree of nanocrystallization on the amorphous matrix may also lead to embrittlement of the BMG composite [13]. This work aims to combine the two approaches to obtain a phase-separated BMG with some nanocrystal and a BMG composite with large plasticity. Based on the above aim, a new bulk metallic glass composite $\mathrm{Zr}_{52} \mathrm{Cu}_{42} \mathrm{Al}_{5.5} \mathrm{Nb}_{0.5}$ has been developed by minor $\mathrm{Nb}$ addition in $\mathrm{Zr}_{52} \mathrm{Cu}_{42.5} \mathrm{Al}_{5.5}$ bulk metallic glass, which is based on alloy design and microalloying. The bulk metallic glass composite has a dual-amorphous matrix with partial nanocrystals, and the room compressive plasticity can reach above $13 \%$. The deformation of this composite has also been studied, which implies the nanocrystallization around shear bands (SBs) occurs during the deformation process. 


\section{Experimental}

The as-cast alloy of $\mathrm{Zr}_{52} \mathrm{Cu}_{42.5-\mathrm{x}} \mathrm{Al}_{5.5} \mathrm{Nb}_{\mathrm{x}}(\mathrm{x}=0$ and 0.5 atom\%) was prepared by alloying of $\mathrm{Zr}, \mathrm{Cu}, \mathrm{Al}$ and $\mathrm{Nb}$ metals (the purity was over 99.9 mass\%) in an arc-melting with a $\mathrm{Zr}$-getter and argon atmosphere. Each alloy was remelted at least three times in order to ensure the compositional homogeneity. The cylindrical samples with $2 \mathrm{~mm}$ in diameter and $5 \mathrm{~cm}$ in length were obtained by suction casting in a copper mold. The structure was confirmed by an X-ray diffractometer (XRD, Bruker D8, Bruker, Billerica, MA, USA, ADVANCE Cu K $\alpha$ ). A room-temperature compressive test was measured by an ETM105D mechanical tester with a strain rate at $2 \times 10^{-4} \mathrm{~s}^{-1}$. The samples were cut $4 \mathrm{~mm}$ in length from the as-cast cylinders, and the ends of the samples were polished carefully by emery paper for the compressive test. After the compressive test, the fracture surfaces were investigated by scanning electron microscopy (SEM, LEO1430VP, Zeiss, Jena, Germany). The microstructure was examined by a high-resolution transmission electron microscopy (HRTEM, Tecnai G2 F20, FEI, Hillsboro, OR, USA).

\section{Results and Discussion}

In order to initially identify the structure of the alloys, $\mathrm{Zr}_{52} \mathrm{Cu}_{42.5-\mathrm{x}} \mathrm{Al}_{5.5} \mathrm{Nb}_{\mathrm{x}}(\mathrm{x}=0$ and 0.5 atom\%) was measured for XRD. As shown in Figure 1, it can be seen that there was a typical halo peak and no crystal peaks for the as-cast alloy $\mathrm{Zr}_{52} \mathrm{Cu}_{42.5} \mathrm{Al}_{5.5}$, indicating that $\mathrm{Zr}_{52} \mathrm{Cu}_{42.5} \mathrm{Al}_{5.5}$ with $2 \mathrm{~mm}$ in diameter was amorphous in nature. However, the XRD pattern of $Z_{52} \mathrm{Cu}_{42.5} \mathrm{Al}_{5.5}$ BMG shows a sharp crystallization peak on the halo peak for the alloy $\mathrm{Zr}_{52} \mathrm{Cu}_{42} \mathrm{Al}_{5.5} \mathrm{Nb}_{0.5}$. It indicates that $\mathrm{Zr}_{52} \mathrm{Cu}_{42} \mathrm{Al}_{5.5} \mathrm{Nb}_{0.5}$ was a bulk metallic glass composite, and this crystalline phase peak was an indication of a CuZr phase.

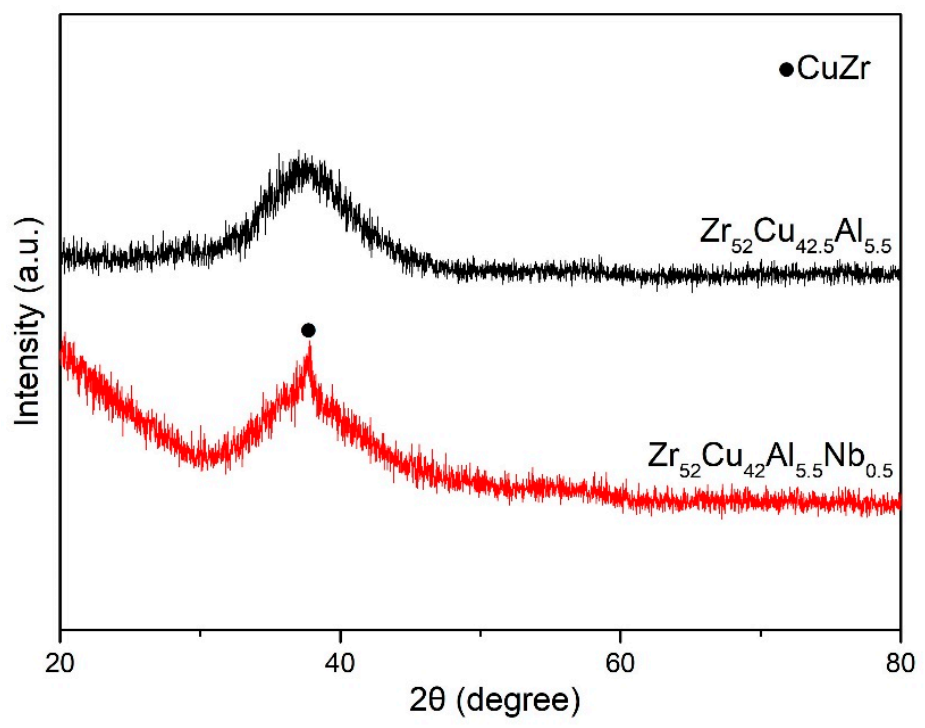

Figure 1. The $\mathrm{XRD}$ pattern of $\mathrm{Zr}_{52} \mathrm{Cu}_{42.5-\mathrm{x}} \mathrm{Al}_{5.5} \mathrm{Nb}_{\mathrm{x}}(\mathrm{x}=0$ and 0.5 atom\%).

The compressive engineering stress-strain curves at room temperature obtained for the as-cast $\mathrm{Zr}_{52} \mathrm{Cu}_{42.5-\mathrm{x}} \mathrm{Al}_{5.5} \mathrm{Nb}_{\mathrm{x}}(\mathrm{x}=0$ and 0.5 atom\%) cylinders are presented in Figure 2. The compressive curves keep a linear elasticity about $2 \%$ before their yielding strength at 1610 and $1555 \mathrm{MPa}$, respectively. However, the $\mathrm{Zr}_{52} \mathrm{Cu}_{42} \mathrm{Al}_{5.5} \mathrm{Nb}_{0.5} \mathrm{BMG}$ composite had a larger plastic deformation of about $13.1 \%$ than that of $\mathrm{Zr}_{52} \mathrm{Cu}_{42.5} \mathrm{Al}_{5.5} \mathrm{BMG}$ at $0.5 \%$. These results show that the plasticity at a room temperature of $\mathrm{Zr}_{52} \mathrm{Cu}_{42} \mathrm{Al}_{5.5} \mathrm{Nb}_{0.5}$ BMG composite could be observably improved by the minor addition of $\mathrm{Nb}$ in $\mathrm{Zr}_{52} \mathrm{Cu}_{42.5} \mathrm{Al}_{5.5}$ BMG. 


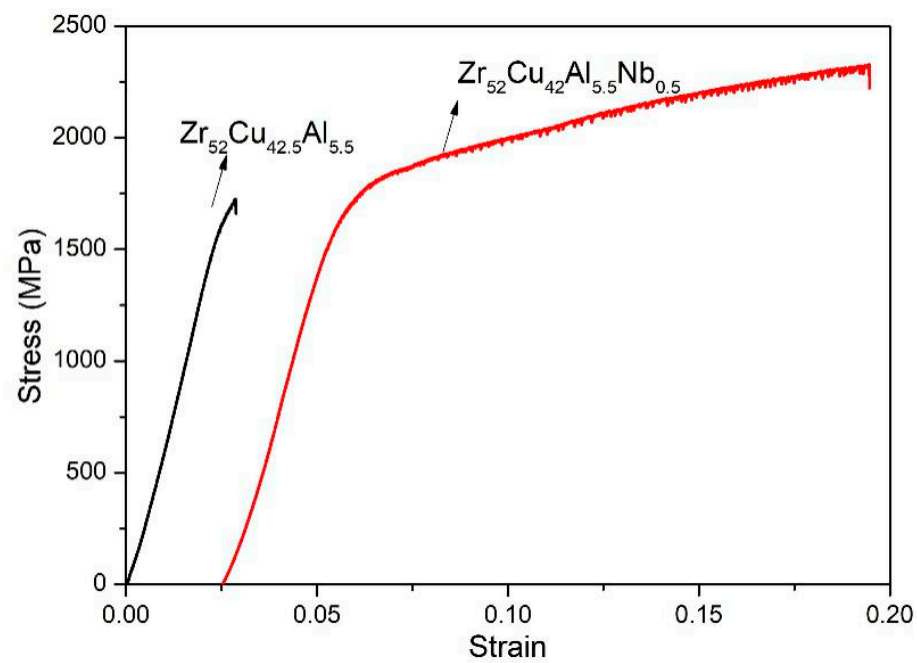

Figure 2. Compressive loading strain-stress curves of $\mathrm{Zr}_{52} \mathrm{Cu}_{42.5-\mathrm{x}} \mathrm{Al}_{5.5} \mathrm{Nb}_{\mathrm{x}}(\mathrm{x}=0$ and 0.5 atom\%) specimens.

The fracture and lateral surfaces of $\mathrm{Zr}_{52} \mathrm{Cu}_{42.5-\mathrm{x}} \mathrm{Al}_{5.5} \mathrm{Nb}_{\mathrm{x}}(\mathrm{x}=0$ and 0.5 atom\%) are presented in Figure 3.
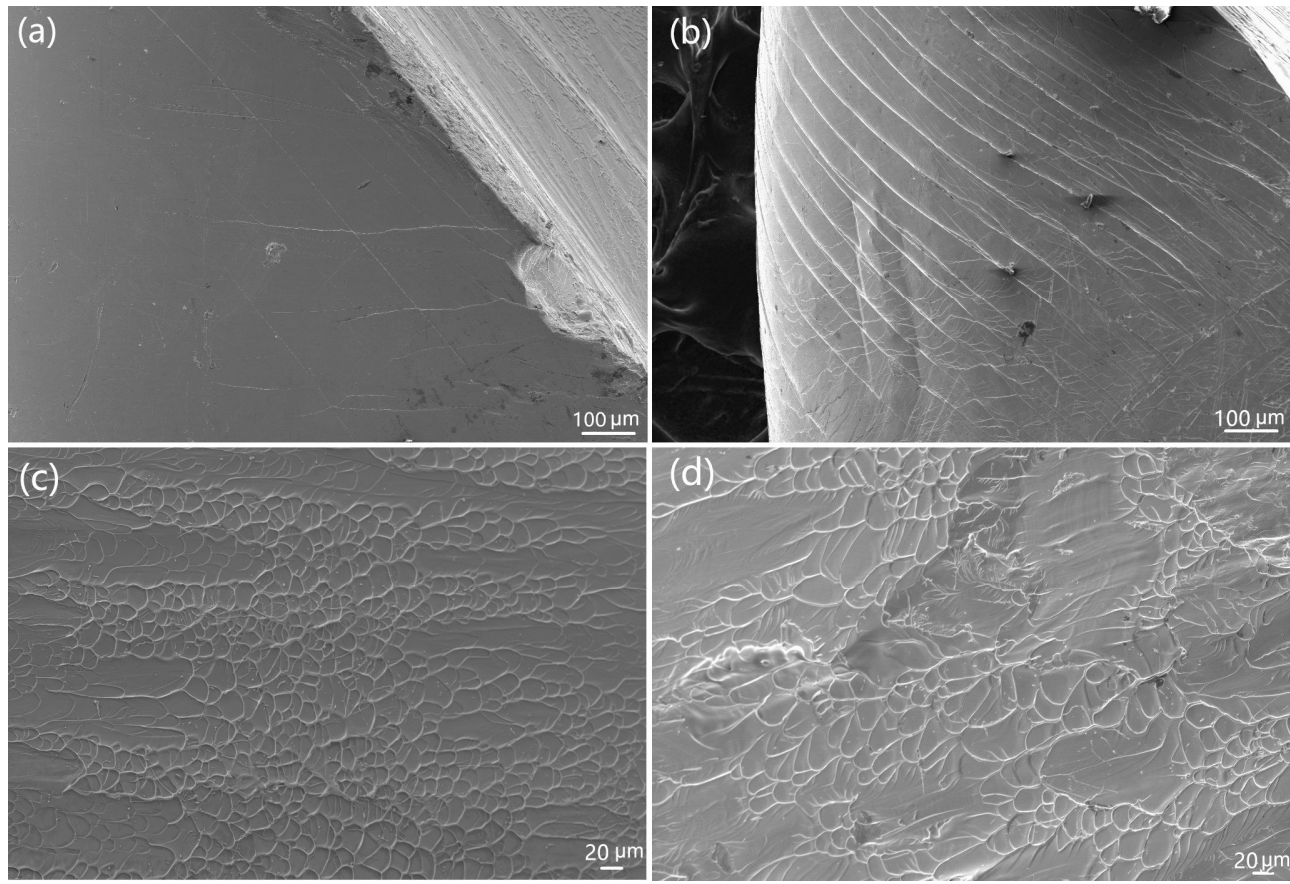

Figure 3. SEM micrographs of the lateral and fracture for $\mathrm{Zr}_{52} \mathrm{Cu}_{42.5} \mathrm{Al}_{5.5} \mathrm{BMG}(\mathbf{a}, \mathbf{c})$ and $\mathrm{Zr}_{52} \mathrm{Cu}_{42} \mathrm{Al}_{5.5} \mathrm{Nb}_{0.5}$ BMG composite $(\mathbf{b}, \mathbf{d})$.

As shown in Figure 3a,c, there were only a few paralleled shear bands on the lateral of $\mathrm{Zr}_{52} \mathrm{Cu}_{42.5} \mathrm{Al}_{5.5} \mathrm{BMG}$, and only a typical homogeneous dimple-like pattern on the fracture, indicating the poor plastic deformation of this alloy. However, a mass of multiple and branched shear bands appeared on the lateral surface of the $\mathrm{Zr}_{52} \mathrm{Cu}_{42} \mathrm{Al}_{5.5} \mathrm{Nb}_{0.5}$ BMG composite as shown in Figure $3 \mathrm{~b}$, which indicates larger plasticity than $\mathrm{Zr}_{52} \mathrm{Cu}_{42.5} \mathrm{Al}_{5.5}$ BMG. The fracture surface presents some inhomogeneity. In addition to the vein-like pattern, there are some river-like branches and coarse zones as shown in Figure 3d.

Then, why does the $\mathrm{Zr}_{52} \mathrm{Cu}_{42} \mathrm{Al}_{5.5} \mathrm{Nb}_{0.5}$ BMG composite have a larger plasticity than $\mathrm{Zr}_{52} \mathrm{Cu}_{42.5} \mathrm{Al}_{5.5} \mathrm{BMG}$ and what is the plasticity originated from? In order to understand the intrinsic 
mechanism for the pronounced plasticity of the $\mathrm{Zr}_{52} \mathrm{Cu}_{42} \mathrm{Al}_{5.5} \mathrm{Nb}_{0.5} \mathrm{BMG}$ composite, we now focused on its as-cast and after deformed microstructure. Firstly, we tried to deeply check the microstructure of the as-cast $\mathrm{Zr}_{52} \mathrm{Cu}_{42} \mathrm{Al}_{5.5} \mathrm{Nb}_{0.5}$ BMG composite. There was only a diffusive halo for the as-cast $\mathrm{Zr}_{52} \mathrm{Cu}_{42.5} \mathrm{Al}_{5.5}$ as shown in Figure 4a. The HRTEM micrograph in Figure $4 \mathrm{~b}$ also shows a homogeneous structure for $\mathrm{Zr}_{52} \mathrm{Cu}_{42.5} \mathrm{Al}_{5.5}$. Compared with $\mathrm{Zr}_{52} \mathrm{Cu}_{42.5} \mathrm{Al}_{5.5} \mathrm{BMG}$, the as-cast $\mathrm{Zr}_{52} \mathrm{Cu}_{42} \mathrm{Al}_{5.5} \mathrm{Nb}_{0.5}$ alloy presents a diffusive halo with some crystal diffraction spots as shown in Figure 4c, indicating the amorphous and nanocrystals structure of the alloy. Compared with the XRD pattern, it shows that some of nanocrystals present in the sample from the selected-area electron diffraction (SAED) pattern of the sample, that maybe induced during the process of the TEM sample preparation. In addition, it also presents some dark and bright droplet-like. Further magnification of the TEM micrograph is shown in Figure $4 \mathrm{~d}$. This image shows that the bright droplet-like was about $5-10 \mathrm{~nm}$ in diameter, which was also of an amorphous structure like the glassy matrix (see the upper right corner of Figure 4d). However, the dark droplet-like was a nanocrystal with about $5 \mathrm{~nm}$ in diameter, which could be determined as the CuZr phase by careful calibration.

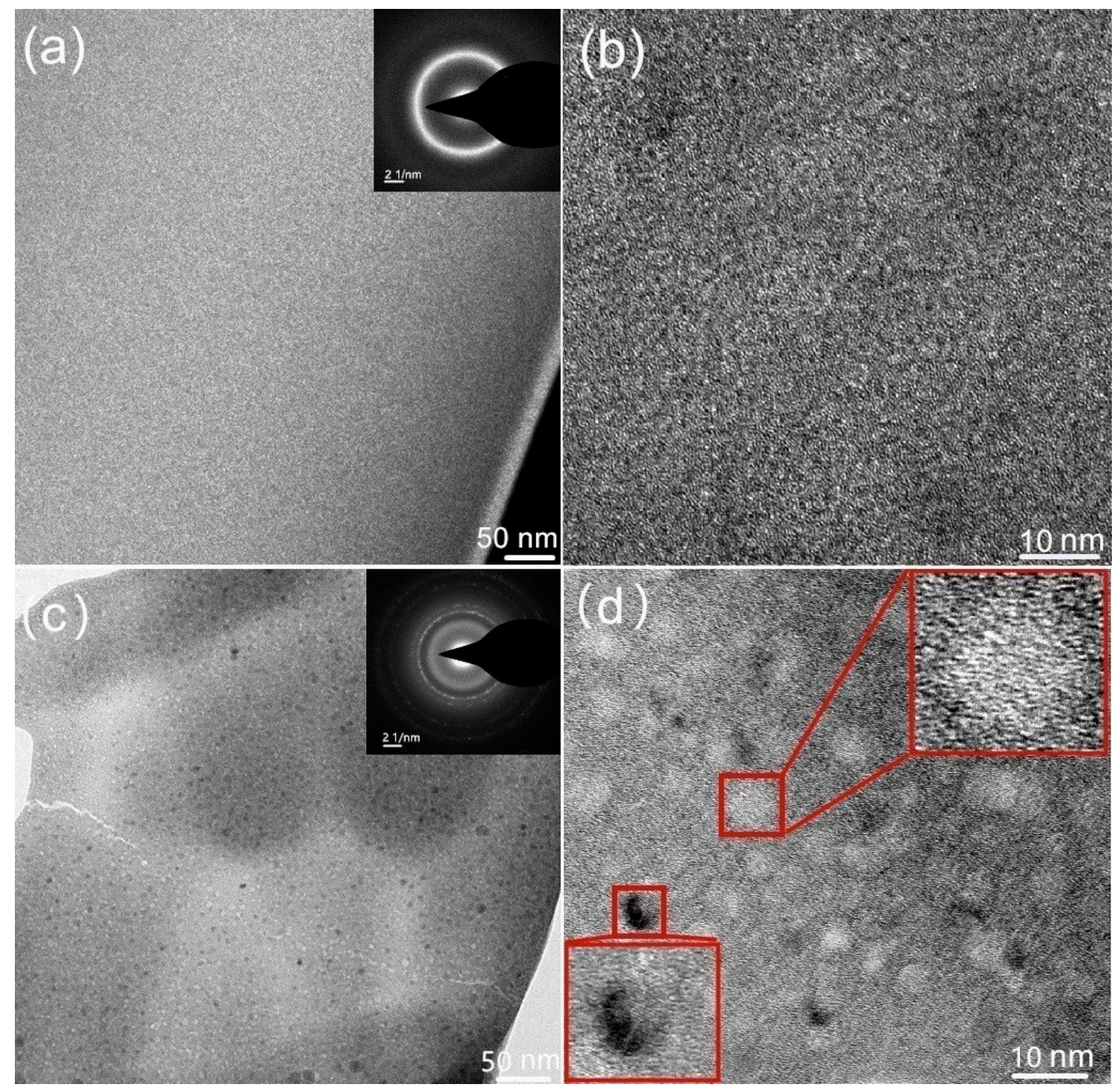

Figure 4. (a) Bright-field TEM micrograph and the selected-area electron diffraction patterns of the as-cast $\mathrm{Zr}_{52} \mathrm{Cu}_{42.5} \mathrm{Al}_{5.5}$ alloy; (b) HRTEM micrograph for the as-cast $\mathrm{Zr}_{52} \mathrm{Cu}_{42.5} \mathrm{Al}_{5.5}$ alloy; (c) Bright-field TEM micrograph and the selected-area electron diffraction patterns of the as-cast $\mathrm{Zr}_{52} \mathrm{Cu}_{42} \mathrm{Al}_{5.5} \mathrm{Nb}_{0.5}$ alloy and (d) HRTEM micrograph for the as-cast $\mathrm{Zr}_{52} \mathrm{Cu}_{42} \mathrm{Al}_{5.5} \mathrm{Nb}_{0.5}$ alloy. 
Figure 5 shows the scanning TEM (S-TEM) micrograph and distribution of the $\mathrm{Cu}, \mathrm{Zr}, \mathrm{Al}, \mathrm{Nb}$ and $\mathrm{O}$ atoms for the as-cast $\mathrm{Zr}_{52} \mathrm{Cu}_{42} \mathrm{Al}_{5.5} \mathrm{Nb}_{0.5}$ alloy. It can be seen that some chemical or structural heterogeneity existed on the amorphous matrix, and an obvious chemical fluctuation existed for the distribution of $\mathrm{Cu}$ atoms, i.e., the droplet-like, and slight of $\mathrm{Zr}$ atoms. There was an $\mathrm{Nb}$-rich zone and a $\mathrm{Cu}$-rich zone from the $\mathrm{Nb}-\mathrm{Cu}$ distribution. It seems that minor $\mathrm{O}$ was distributed in the sample, which may be introduced during the ion polishing.
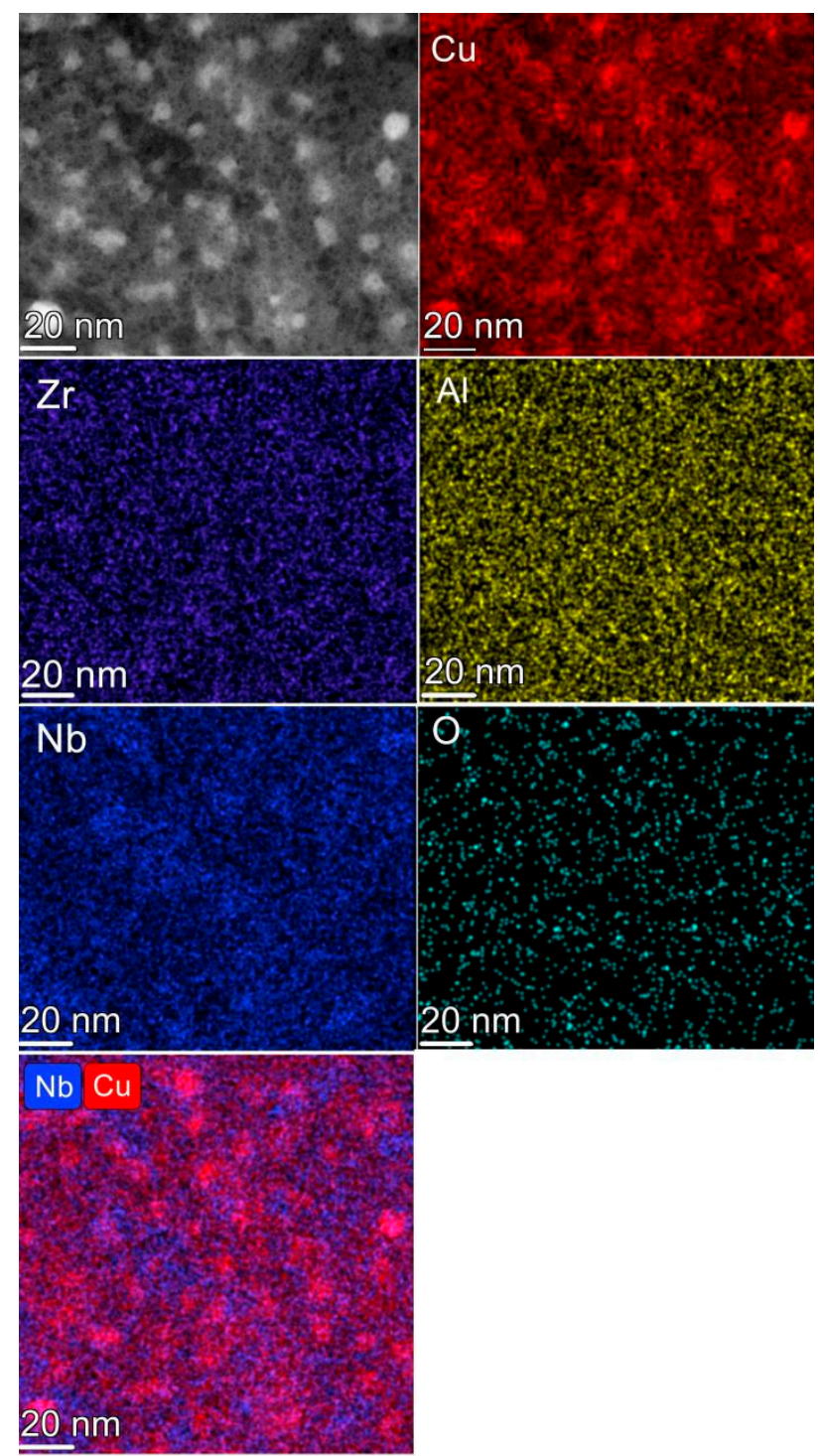

Figure 5. S-TEM micrograph and the elementary distribution of the as-cast $\mathrm{Zr}_{52} \mathrm{Cu}_{42} \mathrm{Al}_{5.5} \mathrm{Nb}_{0.5}$ alloy.

The uniform distributions should be caused by phase separation, which lead to an inhomogeneous structure and play an important role in the plastic behavior [14]. It has been proposed that the inhomogeneous structure can improve the plasticity of MGs via the formation of multiple shear bands [15]. For this alloy, the addition of micro $\mathrm{Nb}$ may provide the driving force for phase separation since the heat of mixing between $\mathrm{Cu}$ and $\mathrm{Nb}$ is positive $\left(\Delta H_{\mathrm{Cu}-\mathrm{Nb}}=3 \mathrm{~kJ} / \mathrm{mol}\right)$ [16]. According to Inoue's proposal [17], the positive $\Delta H$ may degrade the glass forming ability (GFA) at the same time. Therefore, some of the amorphous will occur to crystallize during the cooling process. Interestingly, the nanocrystallization seemed to firstly choose the droplet-like amorphous, rather than the amorphous matrix, which was observed for the first time. The reason may be the stability of these two amorphous structures was not the same. The droplet was in the nanoscale, which may be more unstable than the 
amorphous matrix. From the above discussions, it is the formation for the special dual-amorphous and nanocrystal structures for the $\mathrm{Zr}_{52} \mathrm{Cu}_{42} \mathrm{Al}_{5.5} \mathrm{Nb}_{0.5} \mathrm{BMG}$ composite. The dual-amorphous structure and nanocrystals were considered to be synergistically improving the plasticity of the alloy. According to the shear transformation zone (STZ) model, the plastic flow of metallic glass occurred through the formation and cooperative shearing of unstable STZs. In this alloy, uniform distribution of inhomogeneous structures and nanocrystals could induce inhomogeneous stress zones, which would lead to inhomogeneous distribution of the STZs in the amorphous matrix, resulting in the nucleation of multiple shear bands and improving the plasticity of the alloy.

Then, we focused on the structure after the deforming process of the $\mathrm{Zr}_{52} \mathrm{Cu}_{42} \mathrm{Al}_{5.5} \mathrm{Nb}_{0.5} \mathrm{BMG}$ composite. Figure 6a shows the TEM image after the deformation of this alloy. Abundant nanocrystals distributed homogeneously in the amorphous matrix, as shown in Figure 6a, which indicates that deformation-induced nanocrystallization took place in the $\mathrm{Zr}_{52} \mathrm{Cu}_{42} \mathrm{Al}_{5.5} \mathrm{Nb}_{0.5}$ alloy. It should be noticed that the amorphous droplets of the as-cast almost disappeared and transformed into nanocrystals, which also indicates that the amorphous droplets were more unstable than the amorphous matrix. The diffraction rings corresponding to the image further confirmed the presence of these nanocrystals. From the SAED pattern, it was hard to determine the structure of the nanocrystals. Therefore, the HRTEM pattern of a nanocrystal, as shown in Figure $6 \mathrm{~b}$, shows a parallel lattice fringe with the spacing of $0.2283 \mathrm{~nm}$, and the inverse Fourier transformation shows that the nanocrystal phase may be corresponding to the body-centered cubic phase of the [1111] crystal zone after a further HRTEM examination as shown in Figure $6 \mathrm{~b}$. From the above results of TEM images, the mechanism for the excellent plasticity of $\mathrm{Zr}_{52} \mathrm{Cu}_{42} \mathrm{Al}_{5.5} \mathrm{Nb}_{0.5}$ could be also understood by the deforming process. It is well known that $\mathrm{BMG}$ is a material in the metastable state. In order to reach a more stable state, BMG may crystallize when some external interference occurs, such as heating [18] and stress [19]. It should be noticed that during the deformation, the temperature of the shear bands could reach more than $400 \mathrm{~K}$ [20]. Owing to a bigger attractive basin for the crystal structure compared with the amorphous matrix, the phase transition tends to occur with larger applied stress during the deformation. Then, the crystal solid solution will precipitate due to the increasing temperature at local positions as a result of the concentration of shear stress. Since the appearance of nanocrystals with the size of $5-10 \mathrm{~nm}$, the propagation of the main shear bands can be suppressed and then tend to branch, resulting in the formation of multiple shear bands. Additionally, the homogeneous nanocrystals formed during the deformation can also change the energy state in shear bands. Thus, the single glass transforms into the nanocrystals, resulting in the partial release of the accumulated internal energy of shear bands. Therefore, the instability of shear bands can be greatly decreased, leading to the final good plasticity of the $\mathrm{Zr}_{52} \mathrm{Cu}_{42} \mathrm{Al}_{5.5} \mathrm{Nb}_{0.5}$ alloy. Compared with other bulk metallic glass composites, such as $\mathrm{Zr}-\mathrm{Ti}-\mathrm{Nb}-\mathrm{Cu}-\mathrm{Ni}-\mathrm{Be}$ induced crystalline $\mathrm{Ti}-\mathrm{Zr}-\mathrm{Nb} \beta$ phase can enhance to $6 \%$ higher than $\mathrm{Zr}$-Ti-Cu-Ni-Be BMG [21], the in-situ dendrite containing Cu-Zr-Al-Co composites exhibit obvious work hardening during the tensile process due to the transformation induced plasticity (TRIP) effect of in-situ dendrites [10], this work is different in two ways. On the one hand, the structure is different from the $\mathrm{Zr}-\mathrm{Ti}-\mathrm{Nb}-\mathrm{Cu}-\mathrm{Ni}-\mathrm{Be}$ and $\mathrm{Cu}-\mathrm{Zr}-\mathrm{Al}-\mathrm{Co}$. Dual-amorphous and nanocrystals can be found in the as-cast $\mathrm{Zr}_{52} \mathrm{Cu}_{42} \mathrm{Al}_{5.5} \mathrm{Nb}_{0.5}$ alloy, the structure of $\mathrm{Zr}-\mathrm{Ti}-\mathrm{Nb}-\mathrm{Cu}-\mathrm{Ni}-\mathrm{Be}$ and $\mathrm{Cu}-\mathrm{Zr}$-Al-Co were single amorphous with crystals, and the size of the crystals in this work were smaller than $\mathrm{Zr}-\mathrm{Ti}-\mathrm{Nb}-\mathrm{Cu}-\mathrm{Ni}-\mathrm{Be}$ and $\mathrm{Cu}-\mathrm{Zr}$-Al-Co BMG composites. On the other hand, there was a deformation-induced nanocrystallization for the $\mathrm{Zr}_{52} \mathrm{Cu}_{42} \mathrm{Al}_{5.5} \mathrm{Nb}_{0.5}$ alloy, which was the amorphous phase transformed to crystal phase. This is different from the TRIP in $\mathrm{Cu}-\mathrm{Zr}-\mathrm{Al}-\mathrm{Co}$, which was the B2 phase transformed to the B19' phase. From what has been discussed above, both the structure and nanocrystallization lead to good plasticity for the $\mathrm{Zr}_{52} \mathrm{Cu}_{42} \mathrm{Al}_{5.5} \mathrm{Nb}_{0.5}$ BMG composite. 

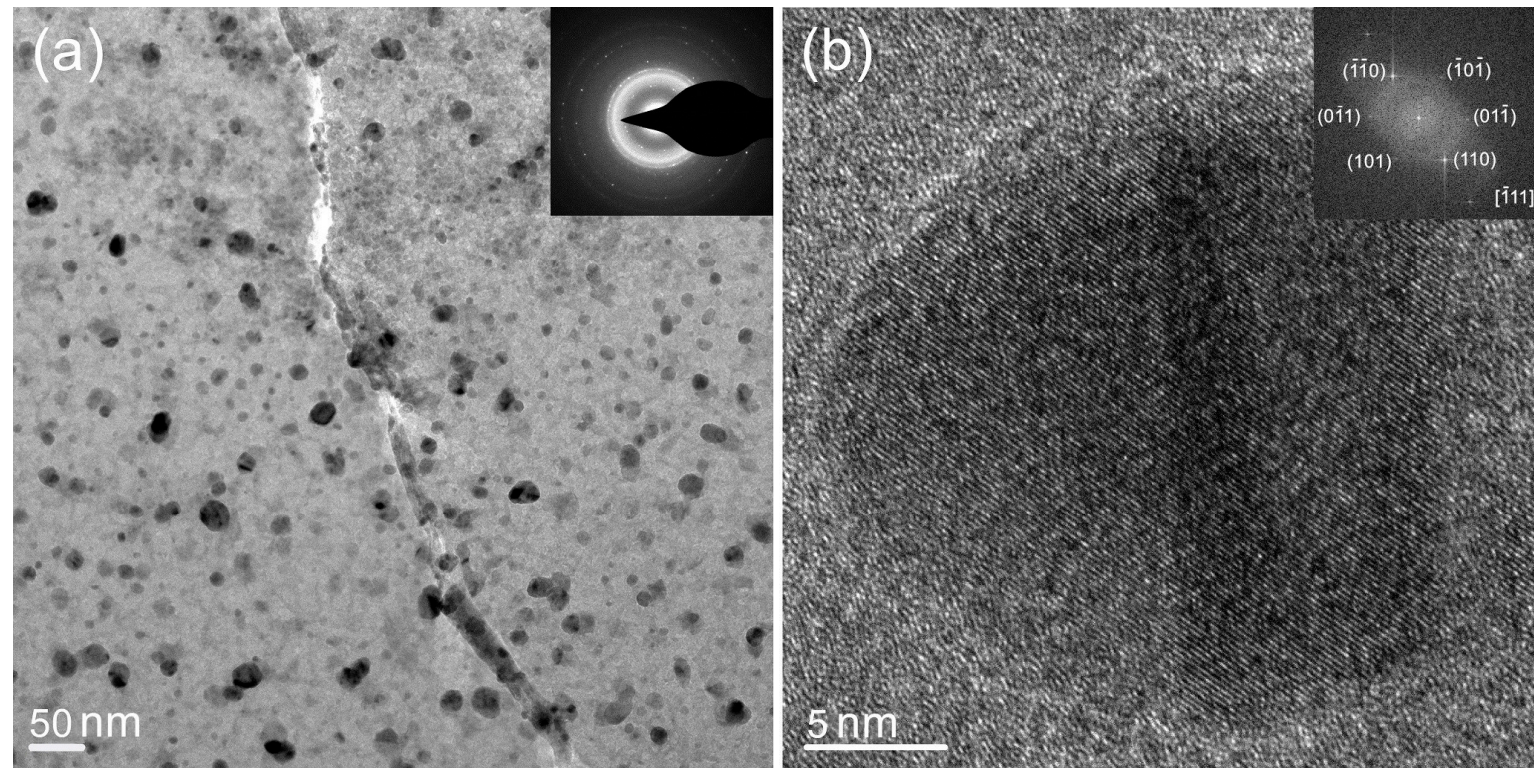

Figure 6. (a) Bright-field TEM image after the deformation and (b) the HRTEM image of the alloy after the application of the compressive test.

\section{Conclusions}

In summary, compressive plasticity of above $13 \%$ was obtained in the $\mathrm{Zr}_{52} \mathrm{Cu}_{42} \mathrm{Al}_{5.5} \mathrm{Nb}_{0.5}$ BMG composite. The good plasticity was attributed to two aspects: one is its special structure of dual-amorphous and nanocrystals and the other is the transformation of the amorphous phase to nanocrystals by the mechanism of deformation-induced nanocrystallization.

Author Contributions: Data curation, formal analysis, investigation and writing-original, T.W.; data curation and formal analysis, X.Y.; investigation and validation Q.L.; supervision and validation, C.C. All authors have read and agreed to the published version of the manuscript.

Funding: The authors are grateful for Scientific Research Program of the Higher Education Institution of Xinjiang (No. XJEDU2019Y003), the Natural Science Foundation of Xinjiang Uygur Autonomous Region of China (No. 2020D01C065), and Doctoral Fund of Xinjiang University (No. BS190201).

Conflicts of Interest: The authors declare no conflict of interest.

\section{References}

1. Wang, W.H.; Dong, C.; Shek, C.H. Bulk metallic glasses. Mater. Sci. Eng. R Rep. 2004, 44, 45-89. [CrossRef]

2. Inoue, A.; Shen, B.L.; Koshiba, H.; Kato, H.; Yavari, A.R. Cobalt-based bulk glassy alloy with ultrahigh strength and soft magnetic properties. Nat. Mater. 2003, 2, 661-663. [CrossRef]

3. Ghaemi, M.; Tavakoli, R.; Foroughi, A. Comparing short-range and medium-range ordering in Cu-Zr and $\mathrm{Ni}-\mathrm{Zr}$ metallic glasses-Correlation between structure and glass form ability. J. Non Cryst. Solids 2018, 499, 227-236. [CrossRef]

4. Qiao, J.C.; Wang, Q.; Pelletier, J.M.; Kato, H.; Casalini, R.; Crespo, D.; Pineda, E.; Yao, Y.; Yang, Y. Structural heterogeneities and mechanical behavior of amorphous alloys. Prog. Mater. Sci. 2019, 104, 250-329. [CrossRef]

5. Wang, T.; Hu, L.; Liu, Y.; Hui, X. Intrinsic correlation of the plasticity with liquid behavior of bulk metallic glass forming alloys. Mater. Sci. Eng. A 2019, 744, 316-323. [CrossRef]

6. Sun, B.A.; Yu, H.B.; Jiao, W.; Bai, H.Y.; Zhao, D.Q.; Wang, W.H. Plasticity of ductile metallic glasses: A self-organized critical state. Phys. Rev. Lett. 2010, 105, 035501. [CrossRef] [PubMed]

7. Li, Q.; Li, J.; Gong, P.; Yao, K.; Gao, J.; Li, H. Formation of bulk magnetic ternary $\mathrm{Fe}_{80} \mathrm{P}_{13} \mathrm{C}_{7}$ glassy alloy. Intermetallics 2012, 26, 62-65. [CrossRef] 
8. Liang, D.D.; Wang, X.D.; Ge, K.; Cao, Q.P.; Jiang, J.Z. Annealing effect on beta-relaxation in a La-based bulk metallic glass. J. Non Cryst. Solids 2014, 383, 97-101. [CrossRef]

9. Wang, W.H. The elastic properties, elastic models and elastic perspectives of metallic glasses. Prog. Mater. Sci. 2012, 57, 487-656. [CrossRef]

10. Wu, Y.; Xiao, Y.; Chen, G.; Liu, C.T.; Lu, Z. Bulk metallic glass composites with transformation-mediated work-hardening and ductility. Adv. Mater. 2010, 22, 2770-2773. [CrossRef]

11. Wang, T.; Lu, W.; Wang, Q.; Liu, Y.; Hui, X. Pronounced plasticity caused by phase separation and $\beta$-relaxation synergistically in Zr-Cu-Al-Mo bulk metallic glasses. Sci. Rep. 2017, 7, 1238. [CrossRef] [PubMed]

12. Park, E.S.; Kim, D.H. Phase separation and enhancement of plasticity in Cu-Zr-Al-Y bulk metallic glasses. Acta Mater. 2006, 54, 2597-2604. [CrossRef]

13. Choi-Yim, H.; Conner, R.D.; Johnson, W.L. In situ composite formation in the Ni-(Cu)-Ti-Zr-Si system. Scr. Mater. 2005, 53, 1467-1470. [CrossRef]

14. Pan, J.; Liu, L.; Chan, K.C. Enhanced plasticity by phase separation in CuZrAl bulk metallic glass with micro-addition of Fe. Scr. Mater. 2009, 60, 822-825. [CrossRef]

15. Liu, Y.H.; Wang, G.; Wang, R.J.; Zhao, D.Q.; Pan, M.X.; Wang, W.H. Super plastic bulk metallic glasses at room temperature. Science 2007, 315, 1385-1388. [CrossRef] [PubMed]

16. Takeuchi, A.; Inoue, A. Classification of bulk metallic glasses by atomic size difference, heat of mixing and period of constituent elements and its application to characterization of the main alloying element. Mater. Trans. 2005, 46, 2817-2829. [CrossRef]

17. Inoue, A. Stabilization of metallic supercooled liquid and bulk amorphous alloys. Acta Mater. 2000, 48, 279-306. [CrossRef]

18. Qin, F.X.; Wang, X.M.; Inoue, A. Effect of annealing on microstructure and mechanical property of a Ti-Zr-Cu-Pd bulk metallic glass. Intermetallics 2007, 15, 1337-1342. [CrossRef]

19. Wang, T.; Si, J.; Wu, Y.; Lv, K.; Liu, Y.; Hui, X. Two-step work-hardening and its gigantic toughening effect in Zr-based bulk metallic glasses. Scr. Mater. 2018, 150, 106-109. [CrossRef]

20. Chen, H.S. Stored energy in a cold-rolled metallic glass. Appl. Phys. Lett. 1976, 29, 328. [CrossRef]

21. Hays, C.C.; Kim, P.; Johnson, W.L. Shear band pattern formation in bulk metallic glasses containing in-situ formed ductile phase dendrite dispersions. Phys. Rev. Lett. 2000, 84, 2901-2904. [CrossRef] [PubMed] 